Chapter published in the Springer Encyclopedia of Gerontology and population Aging, 2020

The publication is available at: https://doi.org/10.1007/978-3-319-69892-2_229-1

To cite this article: Cruz-Martinez G., Cerev G. (2019) Global AgeWatch Index and Insights. In: Gu D., Dupre M. (eds) Encyclopedia of Gerontology and Population Aging. Springer, Cham, DOI:

10.1007/978-3-319-69892-2_229-1

\title{
Global AgeWatch Index and Insights
}

\author{
Cruz-Martinez, Gibran \\ Institute of Public Goods and Policies, \\ Spanish National Research Council \\ (CSIC) \\ Madrid, Spain \\ gibran.cruz@csic.es
}

\author{
Cerev, Gokce \\ Department of Labor Economics \\ and Industrial Relations, Firat University \\ Elazı̆̆, Turkey \\ gcerev@firat.edu.tr
}

\begin{abstract}
:
Global AgeWatch Index and Insights by HelpAge International aim to contribute to achievement of long-term transformative change in respect to ageing and the lives of older people by advocating for better production of timely and good quality data to inform policy and program response.

The Global AgeWatch Index is a composite index that measures quality of life of older people, and ranks countries based on four domains - income security, health status, enabling environment and capability. The index was developed in partnership with Professor Asghar Zaidi. The index was published during 2013-2015.

The Global AgeWatch Insights is a research-based advocacy tool that examines situation of older people in low- and middle-income countries, assesses availability of relevant data and evidence to support the analysis, and identification of policy actions. The Insights are produced in partnership with AARP. The reports were launched in 2018 are planned to be released every three years with a different thematic focus. The first report focuses on the inequities of the health systems in twelve low- and middle-income countries.
\end{abstract}

Keywords: Global Aging Index, Global AgeWatch Insights, International Aging Indicators, Global Aging Data 


\section{Overview}

Life-cycle risks are inherent to every human being. As humans, we desire to go through every stage of life, from childhood to older age. Every stage has social risks associated with it, but older-age could be considered as the most sensitive period of human life (Caspari and Lee 2004).

The global population is aging at unprecedented rates. The number of older-age adults in the world has almost quintupled in the last sixty-five years (see Figure 1). This exponential growth is especially evident, and above the global average, in the geographical regions of Latin America and the Caribbean, Africa and Asia (UNPD 2017). The 906 million older adults above 60 years of age represent 12.3 percent of the world population. See Table 1 for data disaggregated by region.

Figure 1: World population aging from 1950-2015

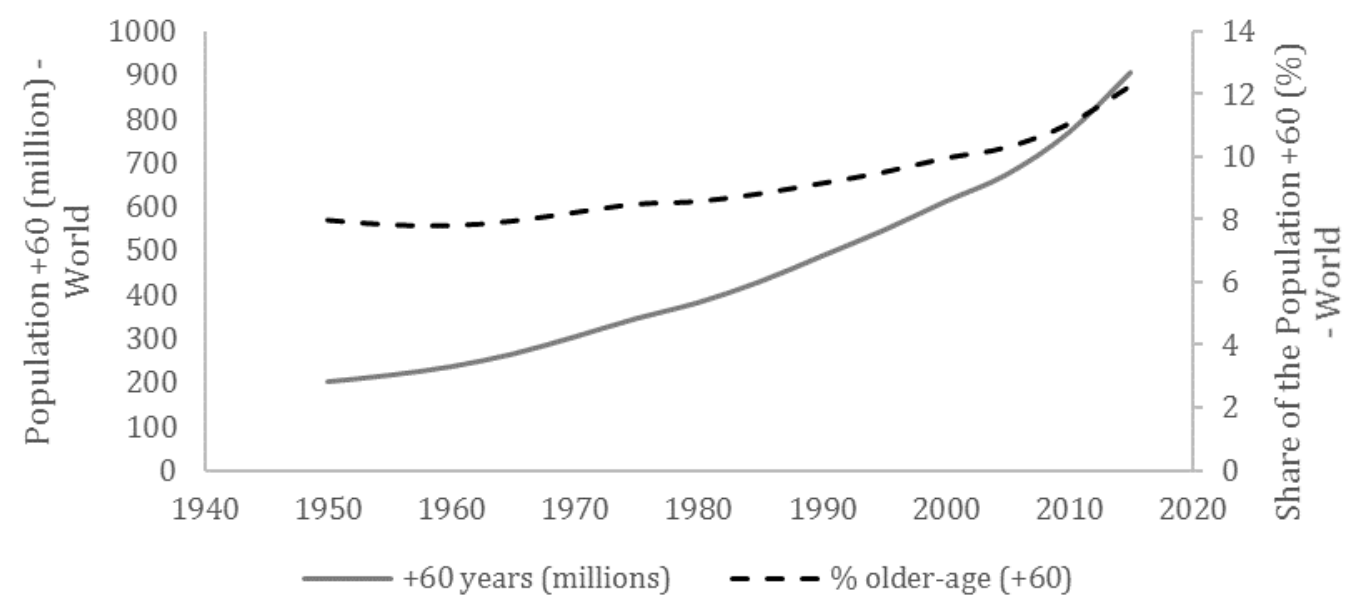

Source: Calculated by the authors with data from UNPD (2017).

The main determinants for this exponential aging are the increase in the quality of human life, the decrease of mortality rates, the decrease of birth rates and the increase in the lifeexpectancy (Stallard 2006). Living longer and healthier lives is a success story. However, policymakers and governments need to consider this when planning and implementing public policy. Systems, practices and norms need to adapt to ageing. Government policy making, planning and implementation must recognize population ageing and needs of older people, 
address barriers to realization of rights of older people, and ensure that quality evidence and data on older people are collected to inform policy.

Table 1: Older-age population by geographical region (2015)

\begin{tabular}{|l|c|c|}
\hline Location & Millions of older-age adults & $\begin{array}{c}\text { The share of older-age adults } \\
\text { (\%) }\end{array}$ \\
\hline World & 906,00 & 12,27 \\
\hline Africa & 64,34 & 5,39 \\
\hline Asia & 513,84 & 11,63 \\
\hline Europe & 176,78 & 23,86 \\
\hline Latin America and the Caribbean & 70,68 & 11,18 \\
\hline Northern America & 73,84 & 20,74 \\
\hline Oceania & 6,52 & 16,49 \\
\hline
\end{tabular}

Source: Calculated by the authors with data from UNPD (2017).

The Global AgeWatch Index was developed to: (i) measure the quality of life of older people; (ii) spotlight susseses and shorcomings of country responses to population ageing; and (iii) stimulate demand for and supply of age-disaggregated data (Mihnovits and Zaidi 2015).

The conceptual framework of the Index draws on the literature review of wellbeing of older people and capabilities approach. It further takes into account priority areas identified in the 2012 United Nations Population Fund (UNFPA) and HelpAge report, Ageing in the XXI century: a celebration and a challenge, and the Madrid International Plan of Action on Ageing.

Global AgeWatch Index is multidimensional as it considers four areas required for the economic and social wellbeing of the older-age population: income security, health status, enabling environment and capability. HelpAge International argues that these four dimensions represent four key domains for older-age people, "covering the most crucial aspects of their wellbeing, experience and opportunities" (HelpAge International 2015, p. 7). The latest 
available data is from 2015, and it covers 96 countries, which includes 60 percent of the world's population at age 60 and over.

Table 2 shows domains and indicators of the Global AgeWatch Index. All indicators are outcomes indicators and most of them are absolute-level indicators (Mihnovits and Zaidi 2015).

Table 2: Global AgeWatch Index domains, indicators, and indicator weights

\begin{tabular}{|l|l|l|l|}
\hline \multicolumn{2}{|c|}{ Global AgeWatch Index } \\
\hline Income Security & Health Status & Capability & Enabling Environment \\
\hline $\begin{array}{l}\text { Pension income } \\
\text { coverage (1) }\end{array}$ & Life expectancy at $60(1)$ & $\begin{array}{l}\text { Employment of older } \\
\text { people }(1)\end{array}$ & Social connections (1) \\
\hline $\begin{array}{l}\text { The poverty rate in } \\
\text { old age (0.5) }\end{array}$ & $\begin{array}{l}\text { Healthy life expectancy } \\
\text { at } 60(1)\end{array}$ & $\begin{array}{l}\text { Educational status of } \\
\text { older people (1) }\end{array}$ & Physical safety (1) \\
\hline $\begin{array}{l}\text { The relative welfare of } \\
\text { older people (0.5) }\end{array}$ & $\begin{array}{l}\text { Psychological wellbeing } \\
(0.5)\end{array}$ & \begin{tabular}{l} 
Civic Freedom (1) \\
\hline $\begin{array}{l}\text { Gross national income } \\
\text { (GNI) per capita (0.5) }\end{array}$
\end{tabular} & $\begin{array}{l}\text { (0.5) to public transport } \\
\text { (1) }\end{array}$ \\
\hline
\end{tabular}

Note: The weight given to each indicator is in parenthesis. It refers to the unit weight used to construct the dimension index. In percentage terms, the HelpAge team assigned the following weights for the income security dimension: 40 percent for pension income coverage, 20 percent for poverty rate, 20 percent for the relative welfare and 20 percent for GNI per capita. These are the weights of the three indicators making the health status dimension: 40 percent for life expectancy, 40 percent for healthy life expectancy, and 20 percent for psychological wellbeing. Each of the two indicators of the capability dimension contributes 50 percent to the dimension index. Finally, each of the four indicators of the enabling environment dimension contributes 25 percent to the dimension index.

Source: (HelpAge International 2015).

The income security dimension highlights the importance of adequate income for sustaining wellbeing in later life. According to the International Labour Organization over 70 percent of the world's population is not adequately covered by social protection. In other words, "only $27 \%$ of the global population enjoys access to comprehensive social security" (ILO 2014b). Forty-eight percent of older adults over pensionable age do not receive a pension, and for many of the pensioners, the benefit levels are inadequate (ILO 2014a). Low participation rates 
in the formal economy and under-institutionalized regressive taxation systems are used to justify the implementation of targeted social pensions throughout the globe (Bastagli 2013; Cruz-Martinez 2019). However, recent research demonstrates that universal social policy is a politically and economically viable policy output because there are multiple options to increase fiscal space and implement a basic universal cash transfer in the Global South (Cruz-Martinez 2018).

The health status domain measures the physical and psychological conditions of older people, and highlights the importance of accessing quality health and care services. . The capability domain measures the employment-levels and education status of older adults. HelpAge International considers these two indicators are good proxies for engagement in the labour market and in the society, as well as for human capital in older people.

Finally, the enabling environment domain includes four indicators chosen by older adults themselves. This domain captures some of the social and physical factors of the environment enabling older adults to be and do what they desire and value.

The Index draws on a mix of data sources, most of which are openly available (i.e. the World Bank, World Health Organization, International Labour Organization, Eurostat, Organisation for Economic Co-operation and Development), and one, Gallup WorldView, is proprietary. Data covers latest available observations for population aged 50 or 60 and over.

The methodology used to construct the Global AgeWatch Index is based on the Human Development Index and is inspired by the Active Ageing Index. First, all 13 indicators are expressed as positive values (e.g., a higher value represents a better outcome). Second, all indicators are normalized (e.g., maximum equals 100 and minimum equals 0 ). Third, the four individual domains indices are constructed using the geometric mean of the individual indicators. Indicators' weights (see Table 2) are assigned based on the judgment of researchers. Fourth, the domains are aggregated into the composite index using the geometric mean. All domains have equal weight (25 percent) in the composite index.).

\section{Results and impact: The Global AgeWatch Index}

The Index was published annually from 2013 to 2015. During this time the number of countries increased from 91 to 96 . In the last edition of the Index, Switzerland ranked first 
while Afghanistan placed last. Mauritius (42) leads the African region, Japan (8) the AsiaPacific region, Panama (20) the Latin America and the Caribbean region, and the Czech Republic (22) the Eastern Europe region. The top seven countries and 18 of the top 20 are located in Western Europe, North America, and Australasia. In contrast, Africa is home to ten of the bottom 20 countries with the Global AgeWatch Index scores. The ranking is generally in line with the income-level of countries.

Global AgeWatch index became a useful advocacy tool as interest among international newspapers as well as national and local outlets helped to amplify key messages, engage new audiences and create opportunities for more in-depth conversations on ageing and development (Gladstone 2015; Anderson 2015). A number of researchers have used the Global AgeWatch Index in their investigations. From determinants of healthy aging (Sadana et al. 2016) to exploring the Index results within the national context (Vidyasova, and Grigoryeva 2016), to proposals to strengthen the composite index with population dynamics (da Silva Francisco 2017), and as a complementary measure of well-being and quality of life to existing indices (e.g., Active Ageing Index) (Zaidi 2015). Additionally, the process of developing the Index contributed to building greater understanding about extent of data gaps which in turn helped to strengthen the call for establishment of the Titchfield City Group on Ageing and Age-disaggregated data.

Reflecting on lessons from publishing the Index HelpAge acknowledged that general awareness of data gaps on ageing and older people has increased and there is a need for a more in-depth national and regional analysis - more nuanced understanding of diversity and inequality in ageing experiences, assessment of what data is available and what is missing at the country level, and more specific policy recommendations on ageing and data (Conboy 2017).

\section{Global AgeWatch Insights 2018}

In 2017 HelpAge International and AARP partnered to redesign the index to become Global AgeWatch Insights. The first edition of Global AgeWatch Insights was launched in December 2018. Rather than presenting an updated and strengthened version of the composite Global AgeWatch Index, the Global AgeWatch Insights 2018 focuses on health, examining the extent 
to which older people's right to health is realized, and the barriers that limit individuals' access to health systems and services. . The Insights consist of the global report profiling 12 low- and middle-income countries (LMICs), Argentina, Colombia, El Salvador, Kenya, Lebanon, Myanmar, Pakistan, Moldova, Serbia, Tanzania, Vietnam, and Zimbabwe, and two in-depth country studies (Tanzania and Vietnam).

The report evidences the inequities of the health systems worldwide and the lack of quality data about ageing and health in LMICs. Among the barriers to older-age population's right to health are age discrimination, monetary poverty, costs of health services, low health literacy and lack of institutional outreach to the older-age population in isolated communities (HelpAge International 2018).

The report also considers that health systems around the globe have not been able to keep pace with, what the HelpAge International considers, two major and interconnected global transitions: an epidemiological and a demographic transition. The epidemiological transition refers to the worldwide pattern of disease that has been shifting from communicable towards non-communicable diseases (NCDs) and the older-age population is disproportionally more affected than younger cohorts. Three-quarter of deaths among people aged 60 and over in LMICs were from NCDs. According to the World Health Organization, non-communicable diseases are more commonly known as chronic diseases. Meanwhile, communicable diseases are spread through physical contact, bites from insects or through the air.

The demographic transition refers to rapid global aging, which is -in part - the result of a decline in the mortality and fertility rates. HelpAge International argues that global health systems need to adapt to these two transitions and develop a more integrated health care system with coordinated services responding holistically instead of targeting specific diseases. Moreover, they argue that the Sustainable Development Goals and global commitment to achieve universal health coverage provide an opportunity to advance realization of human rights for people of all ages, and to provide a pathway for addressing the demographic and epidemiological transitions.

The Global AgeWatch Insights highlights the imperative need for good-quality, timely and individual data that is disaggregated by gender, age, disability and other socio-economic characters. Without it governments, civil society and researchers are not able to accurately measure, understand and respond to the diverse and particular needs of older people, and to 
monitor realization of the right to health for all. The authors of the report cite a number of challenges when they scoped for data on older people across the twelve profile countries. For example, (a) data is difficult to access, not available or inexistent, (b) metadata is missing for several datasets, (c) the wording of the survey questions varied considerably affecting the comparability of data, (d) age caps in international surveys, (e) and paucity of surveys on ageing.

The report identifies a number of actions that should be taken by governments and national statistical agencies to make data, and health and care systems inclusive of ageing, and to realise older people's right to health.

In May 2019, two companion country studies were released - Vietnam and Tanzania Insights: the right to health and access to universal health coverage for older people (HelpAge International 2019a and 2019b). Despite differences in how health services and financial protection are provided in each country, both nations face similar issues: (i) many older people remain excluded from accessing health services and financial protection; (ii) older men and women struggle to access affordable, appropriate and good quality care due to low level of awareness of their right to health and lack of recognition of those rights by health and social protection systems; (iii) data systems designed to inform the planning and delivery of health services exclude older people (HelpAge International 2019c).

\section{Future Directions of Research}

Future editions of the Global AgeWatch Insights are expected to examine ageing and situations of older men and women in LMICs from a global and national perspectives. Unfortunately, the lack of gender-disaggregated data prevented HelpAge International to break down the three Global AgeWatch Index editions (e.g., 2013, 2014, and 2015) nor the latest Global AgeWatch Insights by gender. According to Albone, Beales, \& Mihnovits (2014, p. 1), gender disaggregated data for older adults is often not collected, and when it does exist, it is not fully utilized or analyzed. The four domains could be strengthened by including additional indicators operationalizing additional facets of older adults' well-being. The unavailability of comparable cross-country disaggregated data is still a significant limitation. 
The Global AgeWatch Index and the Global AgeWatch Insights are useful tools to advance awareness of gaps in the post-2015 development agenda regarding ageing and older people, and to highlight the need for more comprehensive data and disaggregated by geographical region, age, and gender (Beales, Russell-Moyle, and Mikkonen-Jeanneret 2014).

\section{Acknowledgement}

We wish to thank Aleksandr Mihnovits from HelpAge International for his helpful comments.

\section{References}

Albone, R., Beales, S., \& Mihnovits, A. (2014). Older people count: Making data fit for purpose. Global AgeW atch Policy Brief, 4, 1-6, HelpAge International.

Anderson, M. (2015). Poor monitoring renders millions of elderly people worldwide 'invisible'. The Guardian, September 9, Retrieved from: https://www.theguardian.com/globaldevelopment/datablog/2015/sep/09/global-age-watch-index-2015-elderly-people-invisiblehelpage-international

Bastagli, F. (2013). Feasibility of social protection schemes in developing countries. Brussels: European Union.

Beales, S., Russell-Moyle, L., \& Mikkonen-Jeanneret, E. (2014). A post-2015 framework for all ages: Transforming the future for youth and older people. Global AgeW atch Policy Brief, 5, HelpAge International.

Caspari, R., \& S.H. Lee (2004). Older age becomes common late in human evolution. Proceedings of the National Academy of Sciences of the United States of America, 101(30), 10895-10900, doi:10.1073/pnas.0402857101.

Conboy, P. (2017). From Global AgeWatch Index to Global AgeWatch Insights. HelpAge, 15/08/2017. Retrieved from http://www.helpage.org/global-agewatch/blogs/patricia-conboy-29352/fromglobal-agewatch-index-to-global-agewatch-insights-1047/.

Cruz-Martinez, G. (2018). Revenue-Generating Potential of Taxation for Older-Age Social Pensions. Ageing International, 43(4), 415-437, doi:10.1007/s12126-017-9298-2.

Cruz-Martínez, G. (2019), Older-Age Social Pensions and Poverty: Revisiting Assumptions on Targeting and Universalism. Poverty \& Public Policy, 11: 31-56. doi:10.1002/pop4.243

da Silva Francisco, A. A. (2017). 'Gerontogrowth' and population ageing in Africa and the Global AgeWatch Index. The Journal of the Economics of Ageing, 9, 78-89. doi:10.1016/j.jeoa.2016.08.003

Gladstone, R. (2015) Older People Are Invisible in Key Data, Study Warns. The New York Times, Sept. 9, 2015. Retrieved from: https://www.nytimes.com/2015/09/09/world/older-peopleare-invisible-in-key-data-study-warns.html

HelpAge International. (2015). Global AgeWatch Index 2015: Insight report. London: HelpAge International. 
HelpAge International (2018). Global AgeW atch Insights. The right to health for older people, the right to be counted. London, HelpAge International \& AARP. Retrieved from: http://www.globalagewatch.org/.

HelpAge International (2019a). Vietnam Insights. The right to health and access to universal health coverage for older people. London, HelpAge International \& AARP. Retrieved from: http://www.globalagewatch.org/.

HelpAge International (2019b). Tanzania Inisghts. The right to health and access to universal health coverage for older people. London, HelpAge International \& AARP. Retrieved from: http://www.globalagewatch.org/.

HelpAge International (2019c). Universal health coverage is fundamental for addressing health inequalities in Tanzania and Vietnam, new Global AgeWatch reports reveal. Retrieved from: https://www.helpage.org

ILO (International Labour Organization). (2014a). Social protection for older persons: Key policy trends and statistics. Geneva: International Labour Office.

ILO (International Labour Organization). (2014b). World Social Protection Report 2014-15: Building economic recovery, inclusive development and social justice. Geneva: International Labour Office.

Mihnovits, A., \& Zaidi, A. (2015). Global AgeWatch Index 2015: Methodology update. London: HelpAge International.

Stallard, E. (2006). Demographic Issues in Longevity Risk Analysis. The Journal of Risk and Insurance, Vol. 73, No. 4, 575-609.

UNPD (United Nations Development Programme). (2017). World Population Prospects: The 2017 Revision. Percentage of Total Population by Broad Age Groups. https://esa.un.org/unpd/wpp/Download/Standard/Population/.

Vidyasova L and Grigoryeva I (2016). Russia in the international quality of ageing indicies. Zhurnal Sotsiologii i Sotsialnoy Antropologii (The Journal of sociology and social anthropology), vol. XIX, no. $1,181-193$ 